\title{
Using force data to self-pace an instrumented treadmill and measure self-selected walking speed
}

\author{
Seungmoon Song ${ }^{*}$, Hojung Choi and Steven H. Collins
}

\begin{abstract}
Background: Self-selected speed is an important functional index of walking. A self-pacing controller that reliably matches walking speed without additional hardware can be useful for measuring self-selected speed in a treadmill-based laboratory.

Methods: We adapted a previously proposed self-pacing controller for force-instrumented treadmills and validated its use for measuring self-selected speeds. We first evaluated the controller's estimation of subject speed and position from the force-plates by comparing it to those from motion capture data. We then compared five tests of self-selected speed. Ten healthy adults completed a standard 10-meter walk test, a 150-meter walk test, a commonly used manual treadmill speed selection test, a two-minute self-paced treadmill test, and a 150-meter self-paced treadmill test. In each case, subjects were instructed to walk at or select their comfortable speed. We also assessed the time taken for a trial and a survey on comfort and ease of choosing a speed in all the tests.

Results: The self-pacing algorithm estimated subject speed and position accurately, with root mean square differences compared to motion capture of $0.023 \mathrm{~m} \mathrm{~s}^{-1}$ and $0.014 \mathrm{~m}$, respectively. Self-selected speeds from both self-paced treadmill tests correlated well with those from the 10-meter walk test $\left(R>0.93, p<1 \times 10^{-13}\right)$. Subjects walked slower on average in the self-paced treadmill tests $\left(1.23 \pm 0.27 \mathrm{~ms}^{-1}\right)$ than in the 10-meter walk test $\left(1.32 \pm 0.18 \mathrm{~ms}^{-1}\right)$ but the speed differences within subjects were consistent. These correlations and walking speeds are comparable to those from the manual treadmill speed selection test $\left(R=0.89, p=3 \times 10^{-11} ; 1.18 \pm 0.24 \mathrm{~ms}^{-1}\right)$. Comfort and ease of speed selection were similar in the self-paced tests and the manual speed selection test, but the self-paced tests required only about a third of the time to complete. Our results demonstrate that these self-paced treadmill tests can be a strong alternative to the commonly used manual treadmill speed selection test.
\end{abstract}

Conclusions: The self-paced force-instrumented treadmill well adapts to subject walking speed and reliably measures self-selected walking speeds. We provide the self-pacing software to facilitate use by gait researchers and clinicians.

Keywords: Self-paced treadmill, Self-selected walking speed, Force-instrumented treadmill credit to the original author(s) and the source, provide a link to the Creative Commons licence, and indicate if changes were made. The images or other third party material in this article are included in the article's Creative Commons licence, unless indicated otherwise in a credit line to the material. If material is not included in the article's Creative Commons licence and your intended use is not permitted by statutory regulation or exceeds the permitted use, you will need to obtain permission directly from the copyright holder. To view a copy of this licence, visit http://creativecommons.org/licenses/by/4.0/. The Creative Commons Public Domain Dedication waiver (http://creativecommons.org/publicdomain/zero/1.0/) applies to the data made available in this article, unless otherwise stated in a credit line to the data. 


\section{Background}

Self-selected walking speed is one of the main performance indices of walking. It is the speed at which people normally choose to walk and is also known as preferred speed or comfortable speed. Walking speed determines the time required in achieving the primary goal of walking: getting to a destination. Healthy adults normally choose to walk at about $1.3 \mathrm{~m} \mathrm{~s}^{-1}$ although they can walk much faster $\left(>2.0 \mathrm{~ms}^{-1}\right)$ [1]. Normal walking speed likely results from balancing many factors, including energy use, time spent in transit, appearance, and comfort. It has often been observed that self-selected walking speed is close to the speed that minimizes metabolic energy consumption $[2,3]$ or muscle fatigue [4] in traveling a unit distance. Self-selected walking speed also has been emphasized as a promising measure to assess physical health. For example, walking speed is a good predictor of health status and survival rate in older adults $[5,6]$ and a useful measure for rehabilitation progress [7].

There are different ways to measure self-selected walking speeds. A standard method commonly used in physical therapy and gait studies is the so-called 10-meter walk test $[8,9]$. In a 10 -meter walk test, subjects are instructed to walk at their comfortable speed across a $15 \sim 20 \mathrm{~m}$ walkway, and the time taken to traverse the middle 10 $\mathrm{m}$ section is measured with a stopwatch to calculate selfselected walking speed. This process is often conducted multiple times then averaged for reliable measurements. Another common way of measuring self-selected speed is by asking subjects to manually select their comfortable speeds while walking on a treadmill that changes from slow to fast or fast to slow speeds [10-12]. Measuring comfortable speeds on a treadmill is useful for certain cases, such as collecting data in a treadmill-based gait laboratory [13] and studying assistive technologies with immobile systems [14]. On the other hand, this manual selection process requires the subjects to walk at various speeds, which can be time consuming, and to consciously distinguish comfortable from uncomfortable treadmill speeds, which can be confusing for those who are not familiar with walking on a treadmill.

Self-paced treadmills can also be useful in measuring walking speed. A treadmill that can seamlessly adapt to a subject's walking speed can provide an overground-like walking environment and can compensate for shortcomings in the manual speed selection approach. Self-pacing controllers typically consist of two parts, usually treated independently. The first estimates the subject's speed and position. The second controls treadmill speed based on the estimation. The treadmill speed is typically controlled to match subject speed and to keep the subject in the middle of the treadmill $[15,16]$. Various approaches of estimating subject speed and position have been used. One approach is to use a marker-based optical motion capture system [16-18], which is widely used in research laboratories as a part of a commercial virtual reality package [19]. Researchers have evaluated these motion capture based self-paced treadmills by comparing kinematic and kinetic gait features collected on the self-paced treadmill to those during fixed speed treadmill walking [16] and overground walking [18]. In addition, these self-paced treadmills have been used in rehabilitation research for children with cerebral palsy [20,21], individuals with chronic stroke [22], and individuals with transtibial amputation [23]. Other approaches with low-cost sensors or simpler hardware have been proposed as well, such as using a marker-free infrared-based motion sensor [24], an ultrasonic distance sensor [25], a harness with force sensors [26], and force plates on an instrumented treadmill [15].

A self-pacing controller using force-plate data from an instrumented treadmill is attractive because it does not require additional hardware or instrumentation. Feasel and colleagues [15] have proposed such a controller and used it to separately control the belts on a split-belt treadmill for asymmetric gait. They calculated the ground reaction forces and center of pressure from the force-plate data and combined them with a Kalman filter to track walking speed. The study focused on testing the feasibility of improving gait symmetry in hemiparetic patients with a virtual environment that integrated the self-paced treadmill and a visual scene. Although they reported that the hemiparetic patients self-selected to walk at speeds comparable to their overground speeds, a more thorough evaluation of self-selected walking speed on this type of self-paced treadmill would improve our understanding of its efficacy.

Various aspects of a walking speed test protocol can unexpectedly affect gait and self-selected walking speed. For example, the treadmill speed controller can induce changes in gait. The mechanics of walking on a treadmill that moves at a constant speed are identical to overground walking. However, when the treadmill accelerates, the belt reference frame is no longer equivalent to a fixed-ground reference [27]. In fact, some belt speed control dynamics can lead subjects to walk at speeds far from their preferred over-ground speed [28]. People may also choose different speeds for different walking tasks, such as to walk for a preset time or a preset distance. If people wish to minimize their energy cost in the fixed distance task, they should walk at a speed close to their normal overground speed. In order to minimize effort in the fixed time task, however, they should walk very slowly or even stand still [3]. Then again, people might not be familiar with the implications of a fixed-time walking task, or might place higher weights on comfort or appearance, or might use a heuristic that defaults to a typical speed in both tasks. The specifics of the task, such as the target distance, may also 
affect walking speed $[29,30]$. People may also change their walking speed in response to other contextual variations, such as the visual environment [31,32] or auditory cues [33]. Even the details of the verbal instructions provided to participants can have a strong effect on walking speed [34]. Therefore, it is important to validate the self-selected speed test protocol of interest.

A straightforward way of validating a self-selected walking speed test is to compare its measured speeds to those from the standard walking speed test. However, only a few studies have thoroughly compared walking speed on a self-paced treadmill to that during overground walking, and most of those studies were for a motion capture based commercial self-paced treadmill [18, 35]. Van der Krogt and colleagues [35] compared self-selected speeds of typically developing children and children with cerebral palsy in outdoor walking, overground walking in a lab, and walking on a self-paced treadmill in a virtual environment. Children were instructed to "walk at their own preferred, comfortable walking speed." Both groups of children walked the fastest outdoor, about $5 \%$ slower in the lab, and about $10 \%$ slower on the self-paced treadmill. Similarly, Plotnik and colleagues [18] compared self-selected speeds in healthy adults during walking for $96 \mathrm{~m}$ overground, on a self-paced treadmill, and on a self-paced treadmill with a virtual environment. Subjects were instructed to "walk at their own self-selected preferred comfortable speed." Subjects walked on the selfpaced treadmill at speeds comparable to their overground speeds, while they walked slightly faster when a virtual environment was presented. In addition, walking speed converged faster to steady speed with the virtual environment. These tests demonstrate the value of characterizing response to a self-paced treadmill prior to using it to evaluate the effects of other interventions on self-selected walking speed.

Here, we adapt the force-based self-paced treadmill controller proposed by Feasel and colleagues [15] and evaluate two self-selected walking speed tests using it. First, we explain how the proposed self-pacing controller estimates subject speed and position and adjusts the treadmill speed. Then, we evaluate the speed and position estimations of our controller by comparing them with motion capture data. We then validate the use of the self-paced treadmill for measuring self-selected walking speed. We compare self-selected walking speeds measured from five different speed tests: the standard 10-meter overground walk test, a 150-meter overground walk test, a commonly used manual speed selection treadmill test, a 2minute self-paced treadmill test, and a 150-meter selfpaced treadmill test where subjects can see their goal and progress on a monitor. We compare self-selected walking speed in the $10 \mathrm{~m}$ and $150 \mathrm{~m}$ overground conditions to test whether the standard measure well represents speeds in longer bouts of walking. We validate the self-paced treadmill tests by evaluating how well they correlate with the standard measure and by comparing them to the commonly used treadmill test. The 2-minute and 150-meter self-paced treadmill tests are compared to each other to examine whether it is necessary to explicitly motivate subjects to walk at their typical speeds by setting target distance and showing their progress. Finally, we discuss the implications of our findings and potential extension of our self-paced treadmill for rehabilitation and assistive device studies.

\section{Methods \\ Self-pacing Algorithm}

We revised the self-pacing controller for forceinstrumented treadmills proposed by Feasel and colleagues [15]. The central idea is to estimate subject walking speed from foot contact positions and to improve the estimations by incorporating force measurements using a Kalman filter. In our implementation, we track both speed and position with a Kalman filter, which is updated every time step. The filter uses noise matrices determined empirically from motion capture data. We provide a complete description of the algorithm and share the code [36] so that it can be easily used by other researchers.

Our self-pacing controller consists of a subject State Estimator and a treadmill Speed Controller (Fig. 1). The State Estimator takes data from two force plates (thirdorder Butterworth filter; cutoff frequency: $25 \mathrm{~Hz}$ ) and the treadmill speed as input and estimates the subject's speed and position every computational time step, $\Delta t$. Based

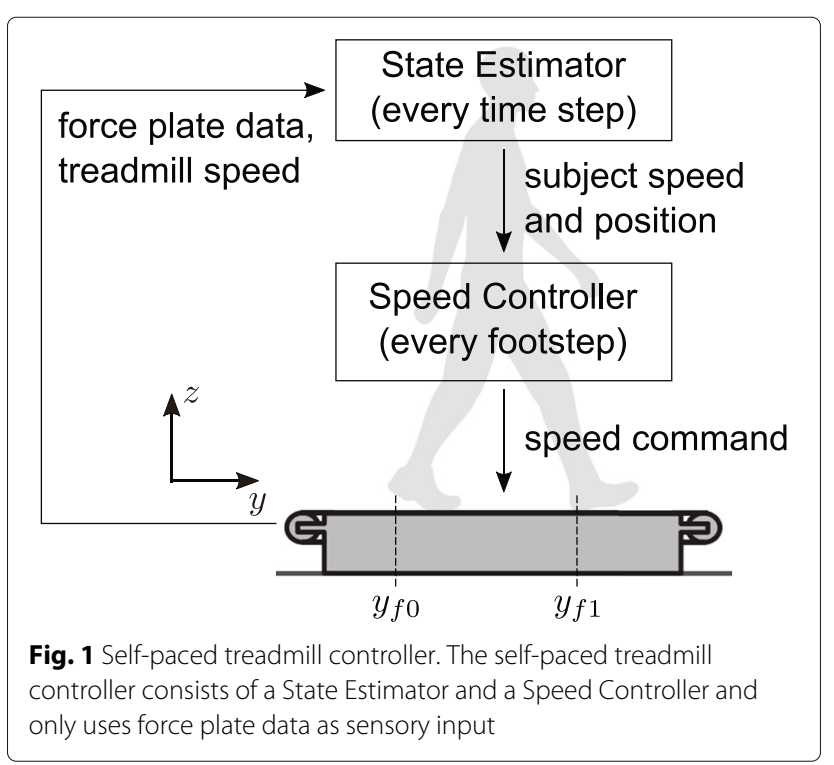


on the estimated speed and position, the Speed Controller adjusts the treadmill speed at the beginning of each footstep.

The State Estimator uses data from the two force plates to measure acceleration, velocity and position of a subject walking on the treadmill and combines the measured values with a Kalman filter. The vertical and fore-aft ground reaction forces (GRFs), $f_{z}$ and $f_{y}$, as well as the center of pressure (COP) are calculated from the force-plate data. Foot contact is detected when the vertical GRF exceeds a certain threshold, $f_{z}>f_{z 0}=20 \%$ of body weight. We defined fore-aft foot position on a given step, $y_{f 1}$, as the $\mathrm{COP}$ at contact detection. Foot position on the prior step in the lab reference frame, $y_{f 0}$, is calculated by the COP at the previous contact plus the integral of the treadmill speed over the time between the contacts $y_{f 1}$ and $y_{f 0}$ are shown in Fig. 1). We then estimate the fore-aft acceleration, velocity and position of the subject in the lab reference frame as

$$
\begin{aligned}
& a_{m e s}=\frac{f_{y}}{m} \\
& \bar{v}_{m e s}=\frac{y_{f 1}-y_{f 0}}{t_{1}-t_{0}}-\bar{v}_{t m} \\
& \bar{p}_{m e s} \approx \frac{y_{f 1}+y_{f 0}}{2}
\end{aligned}
$$

where $m$ is the mass of the human subject, and $t_{0}$ and $t_{1}$ are times when each foot contact occurs, and the variables with a bar indicate mean values during that step (i.e. between consecutive foot contact detections). Eq. 1 is Newton's second law. Eq. 2 estimates the subject's mean speed in the lab reference frame, $\bar{v}_{\text {mes }}$, by subtracting treadmill speed $\left(\bar{v}_{t m}\right)$ from the subject's walking speed. The subject's walking speed is calculated as step length $\left(y_{f 1}-y_{f 0}\right)$ divided by step time $\left(t_{1}-t_{0}\right)$. Eq. 3 defines the subject's mean position, $\bar{p}_{\text {mes }}$, as the middle of the leading and trailing foot placements at a new foot contact.

We implemented a Kalman filter to combine the measurement values $a_{\text {mes }}, \bar{v}_{\text {mes }}$ and $\bar{p}_{\text {mes }}$ to continuously estimate the subject's speed and position (Table 1). The filter keeps track of subject speed and position by predicting them every time step from $a_{\text {mes }}$ (Table 1: line 2), and by correcting them with new measurements $\bar{v}_{\text {mes }}$ and $\bar{p}_{\text {mes }}$ every footstep (line 6). The measurement update is conducted when a new foot contact is detected (line 4). The filter rejects steps of unreasonable duration (greater than 1.2 seconds) to skip the measurement update when subjects cross over the belts (e.g. stepping on the left belt with the right foot). The system model, $A$ and $B$ (and the observation model $C=I$ ), describes the relationship between the measurement values according to Newton's second law. The noise matrices, $Q$ and $R$, as well as the initial error covariance matrix $P_{0}$ are determined from data collected in walking sessions, where two subjects walked

Table 1 Pseudo code of Kalman filter for walking speed and position estimation

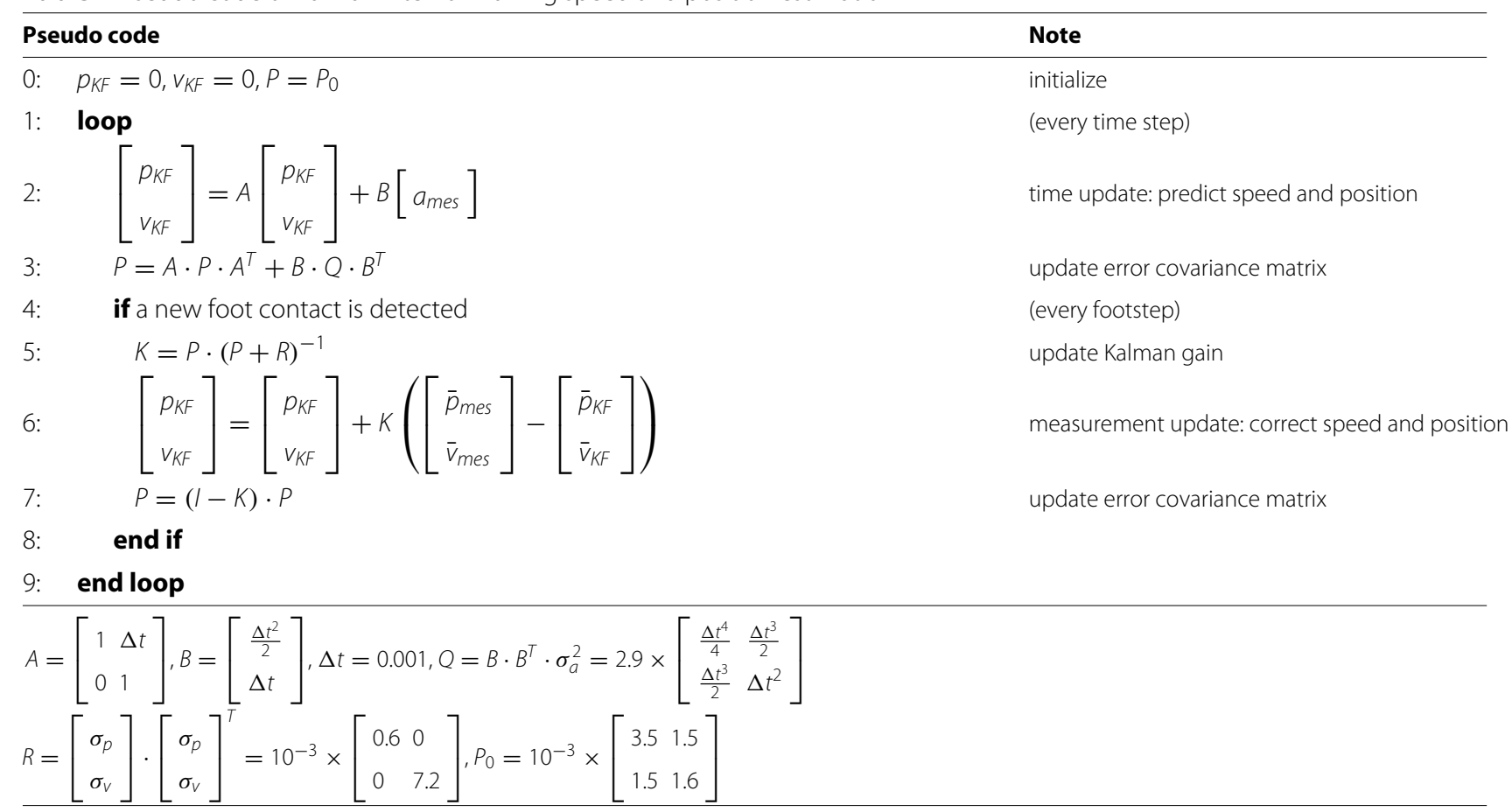

Note that we omitted the observation matrix in lines $5 \sim 7$ as it is the identity matrix $(C=I)$ 
on a treadmill at speeds between 0.8 and $1.8 \mathrm{~m} \mathrm{~s}^{-1}$ in ten one-minute trials. The noise matrices are set based on $\sigma_{a}, \sigma_{v}$ and $\sigma_{p}$ (Table 1), which are the differences in $a_{\text {mes }}, \bar{v}_{\text {mes }}$ and $\bar{p}_{\text {mes }}$, respectively, calculated from forceplate data and motion capture data. $P_{0}$ is set to the mean of the values $P$ converged to at the end of the pilot sessions.

The Speed Controller adjusts the treadmill speed to match subject speed and to keep the subject near a baseline position. It updates the treadmill speed once per footstep when a new foot contact is detected. This is different from other self-paced treadmills in previous studies, where speed adjustment is done at a much faster rate $(30 \sim 120 \mathrm{~Hz})$ [16-18]. Controlling the treadmill speed at a higher frequency can lead to undesired dynamics due to natural speed oscillations during walking. Instead of filtering out these oscillations as in the previous studies, we update it at every footstep. Target treadmill speed is set as

$$
v_{t m, t g t}=\bar{v}_{t m}+G_{\nu} \bar{v}_{K F}+G_{p}\left(\bar{p}_{K F}-p_{0}\right)
$$

where $p_{0}$ is the baseline position, and $\bar{v}_{K F}$ and $\bar{p}_{K F}$ are the subject's mean speed and position during the last step in the lab reference frame estimated from the Kalman filter. Note that, despite the plus signs, Eq. 4 is a stabilizing negative feedback as the treadmill speeds, $v_{t m, t g t}$ and $\bar{v}_{t m}$, are determined in the opposite direction from the subject speed and position, $\bar{v}_{K F}$ and $\bar{p}_{K F}$, in the lab reference frame. The baseline position $p_{0}$ can be predetermined by the experimenter (e.g. $p_{0}=0$ ), manually tuned based on subject feedback, or set based on subject data from familiarization trials. In this study, we used the last approach, where we set $p_{0}$ for each subject as the average subject position measured during the fixed-speed portion of the treadmill familiarization. In theory, $v_{t m, t g t}$ with $G_{v}=1$ will be a speed that matches the subject's estimated walking speed, and $G_{p}=1$ will result in a speed that brings the subject to $p_{0}$ in 1 second. However, a controller with these high gains induced abrupt speed changes, which made it difficult for subjects to walk comfortably. Therefore, we use lower gains of $G_{v}=0.25$ and $G_{p}=0.1$, which we found to be reliable and responsive enough for our study. The treadmill acceleration is set to achieve a target velocity in a certain time as

$$
a_{t m, t g t}=\frac{\left(v_{t m, t g t}-\bar{v}_{t m}\right)}{\Delta t_{t m, t g t}}
$$

where we use $\Delta t_{t m, t g t}=0.5 \mathrm{~s}$, similar to the duration of a walking step.
The code of our self-pacing controller and a graphical user interface are publicly available [36]. The self-pacing controller is implemented in Matlab/Simulink Real-Time and runs on a real-time target machine (Speedgoat) at $1000 \mathrm{~Hz}$ (i.e. $\Delta t=0.001$ ). The real-time target machine receives force-plate data from the instrumented treadmill (Bertec) at the same rate. The graphical user interface implemented in Matlab runs on a desktop machine at 100 $\mathrm{Hz}$ and allows the experimenter to communicate with the real-time target machine. In addition, it receives the target treadmill speed and acceleration from the real-time target machine and commands it to the treadmill.

\section{Experiment 1: State Estimator}

To evaluate the State Estimator, we compared the estimated position and velocity to those from motion capture data. One subject wore a waist belt with four reflective markers and walked on the force-instrumented treadmill for six one-minute trials. Treadmill speed was manually controlled in most of these trials as we wanted to evaluate the State Estimator independently from the Speed Controller. In the first three trials, the treadmill speed was set to $1.3,0.8$ and $1.8 \mathrm{~m} \mathrm{~s}^{-1}$. In the fourth trial, the treadmill speed changed every $10 \mathrm{sec}$ from $0.8,1.0,1.2,1.4,1.6$ to 1.8 $\mathrm{m} \mathrm{s}^{-1}$. In the fifth trial, the same speeds were presented in reverse order. Then, the treadmill was controlled with our self-pacing controller in the last trial. Positions of the four reflective markers were captured with a motion capture system (Vicon Vantage; 8 cameras), sampled in 100 $\mathrm{Hz}$ and low-pass filtered using a third-order Butterworth filter with a cutoff frequency of $20 \mathrm{~Hz}$. The mean of those maker positions, $p_{\text {mocap }}$, and its time derivative, $v_{\text {mocap }}$, were used for evaluation.

We report how the main outputs of the State Estimator $\bar{v}_{K F}$ and $\bar{p}_{K F}$ compare to those from motion capture data. For the mean step velocity, we report the root-mean-square (RMS) differences, $R M S_{\bar{v}}=$ $\sqrt{\frac{1}{n} \sum_{\text {ste }=i}^{n}\left(\bar{v}_{K F, i}-\bar{v}_{\text {mocap }, i}\right)^{2}}$, where $n$ is the total number of steps in a walking trial, and $\bar{v}_{\text {mocap }, i}$ is the mean value of $v_{\text {mocap }}$ on the $i^{\text {th }}$ step. $R M S_{\bar{p}}$ was calculated similarly, but with offset-corrected values for each one-minute trial. This is because $\bar{p}_{K F}$ is not tracking the position of the waist. Our approach does not estimate the absolute position of the person's center of mass, but rather its position relative to the average center of pressure at consecutive foot strikes. Note that any measure of body position can be used to maintain a desirable position on the treadmill by comparing it to a corresponding nominal value, typically determined during a fixed speed calibration trial.

\section{Experiment 2: Self-selected Walking Speed Tests}

We conducted an experiment to evaluate the validity of our self-paced treadmill in measuring self-selected 
walking speeds. Ten healthy adults ( 5 females and 5 males; height: $1.69 \pm 0.08 \mathrm{~m}$; age: $25 \pm 3$ years) participated in the experiment. All subjects participated in a session that consists of familiarization trials and three blocks of five walking speed tests (Fig. 2-a). The familiarization trials were for the subjects to get familiar with walking on our self-paced treadmill and at their comfortable speed in different settings. In addition, the subject's baseline position, $p_{0}$, was found in the fixed-speed portion of the treadmill familiarization. The five walking speed tests in each of the three blocks were presented in random order.
We compared five different self-selected walking speed tests. The settings and measurements of the tests are described in Fig. 2-b. Overground $10 \mathrm{~m}$ is the standard 10meter walk test $[9,37]$ that we used as a reference point in evaluating the outcomes of the other tests. Overground $150 \mathrm{~m}$ is to check whether the standard test represents longer distance walking, as walking distance can affect self-selected speed [30]. Manual Speed Selection is a common way to measure preferred walking speed on a treadmill [10-12]. The correlation between the speed measures in Manual Speed Selection and those in Overground 10

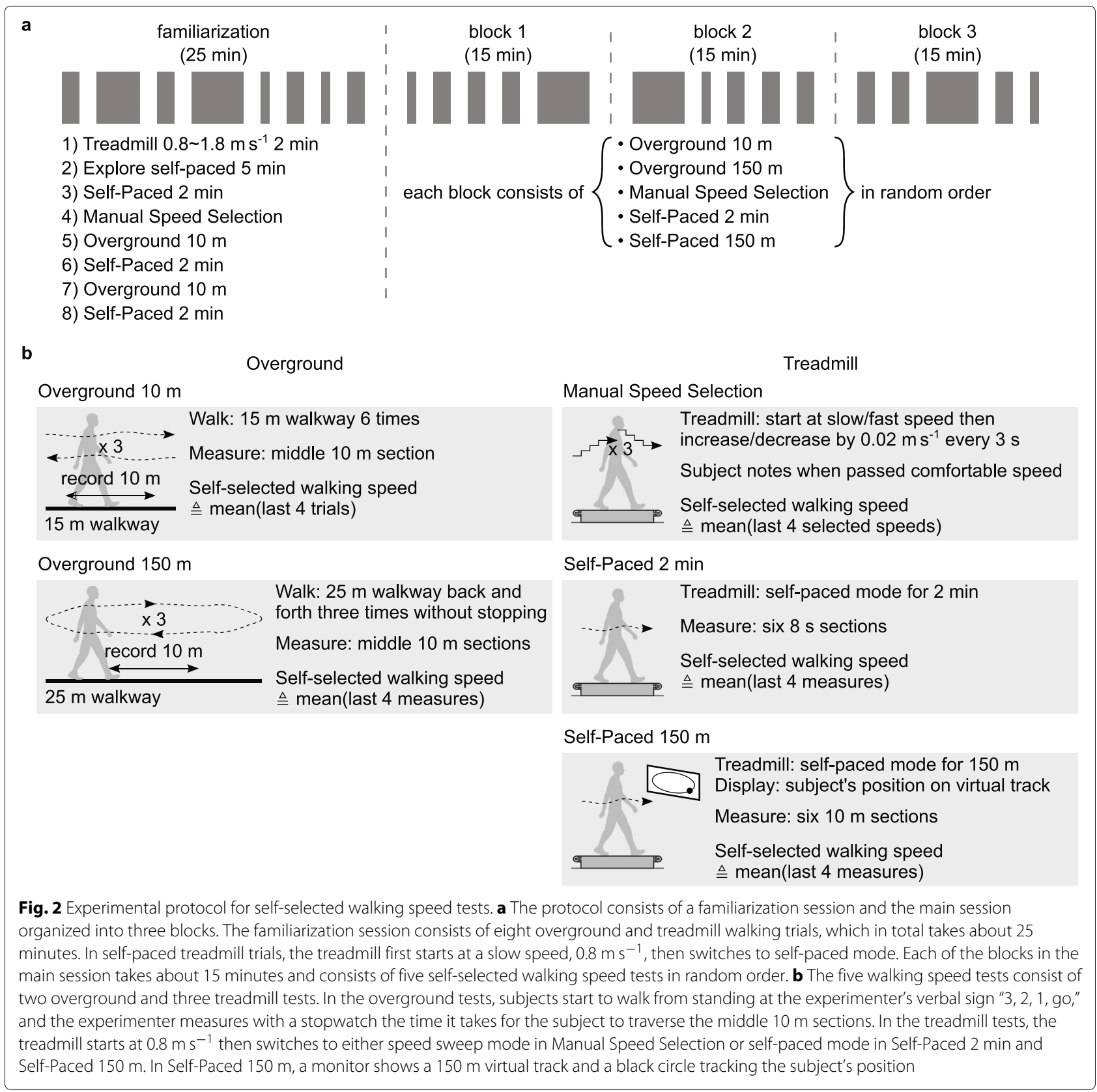


$\mathrm{m}$ will be the benchmark value for our self-paced treadmill tests. Self-Paced 2 min and Self-Paced $150 \mathrm{~m}$ are the tests using our self-paced treadmill. Subjects were informed whether they would walk for $2 \mathrm{~min}$ or $150 \mathrm{~m}$, and, for the latter, subject position was shown on a 150 $\mathrm{m}$ virtual track on a monitor in real-time. We applied both fixed-time and fixed-distance tests on the self-paced treadmill to determine whether it was necessary to motivate participants to walk a given distance in order to obtain self-selected walking speeds that correlated well with overground, fixed-distance tasks.

The self-selected walking speed tests were designed to be coherent and comparable with each other. For example, $150 \mathrm{~m}$ of walking distance in Self-Paced $150 \mathrm{~m}$ was selected to match the distance in Overground $150 \mathrm{~m}$, and the 2 min of walking time in Self-Paced 2 min is the time it takes to walk $150 \mathrm{~m}$ at a typical walking speed of 1.25 $\mathrm{m} \mathrm{s}^{-1}$. Similarly, in Self-Paced $2 \mathrm{~min}$ and Self-Paced 150 $\mathrm{m}$, walking speeds were measured in six sections that correspond to the 10-meter-sections in Overground $150 \mathrm{~m}$. We used consistent instructions in all the walking trials [34]. Subjects were instructed to "walk at a comfortable speed" in the overground and self-paced treadmill tests and to verbally indicate when the treadmill gets "faster (or slower) than what you would choose as a comfortable speed" in Manual Speed Selection. When subjects asked for clarification, we elaborated a comfortable speed as "whatever speed feels natural to you."

We compared self-selected walking speeds measured in each test to the value in the standard overground test. The main evaluation was how well walking speed in each test correlated with the speed in the standard test, Overground $10 \mathrm{~m}$. We also compared self-selected speeds in Self-Paced $2 \mathrm{~min}$ and Self-Paced $150 \mathrm{~m}$ to see whether setting a target walking distance was necessary. In total, we measured 5 sets of 30 self-selected walking speeds: in the five tests, ten subjects walked for three times. For each walking speed test other than Overground $10 \mathrm{~m}$, we report a linear model, $b_{1} v_{O G 10}+b_{0}$, that fits these 30 measurements to those in Overground $10 \mathrm{~m}$ with the minimum mean-squared-error. A test that has a fit of $b_{1}=1$ and $b_{0}=0$ indicates that subjects, on average, are likely to walk at the same speed they walked at in Overground $10 \mathrm{~m}$. We also calculate the Pearson's linear correlation coefficient, $R$, in these pairs of 30 measurements. The correlation coefficient of 1 and 0 correspond to perfect and no correlation, respectively, where a high correlation indicates that much of the variation in measured speeds are captured in the fitted linear model. We considered the linear fit and correlation values to be statistically significant if their $p$-value is smaller than 0.05 .

We calculated the variability of self-selected walking speed in each test to determine whether the selfpaced treadmill tests were as consistent as the standard overground test. To this end, we calculated the standard deviation of the three walking speed measurements of the same subject within each test, $S D_{\text {intra }}$. We compared these standard deviation values in each test to determine whether certain tests show higher variability than others.

We estimated the time taken to conduct one trial of each walking test to determine whether the self-paced treadmill tests required less time than the common treadmill test. We calculated the minimum time used in all trials in our experiments from the recorded data and report their mean and standard deviation for each walking test. The time for an Overground $10 \mathrm{~m}$ trial is calculated as $T_{O G 10}=1.5 \times T_{O G 10, \text { rec }}+6 \times 3$, where $T_{O G 10, \text { rec }}$ is the sum of six recorded times for crossing the $10 \mathrm{~m}$ section, multiplication of 1.5 accounts for the additional $5 \mathrm{~m}$ walk of the $15 \mathrm{~m}$ walkway, and the last term is the three-second countdowns before each of the six bouts. For $T_{O G 150}$ of the Overground $150 \mathrm{~m}$ test, we report the recorded time taken by subjects in completing the $150 \mathrm{~m}$ course plus 3 $\mathrm{s}$ for the countdown. The time used in the Manual Speed Selection, $T_{M S S}$ is reported as the duration the treadmill was controlled in speed sweep mode plus $3 \mathrm{~s}$ for the countdown. Similarly, the times used in Self-Paced $2 \mathrm{~min}, T_{S P 2}$, and Self-Paced $150 \mathrm{~m}, T_{S P 150}$, are reported as the duration the treadmill was in self-paced mode plus $3 \mathrm{~s}$. Most of the reported times underestimate the actual time required for trials; for example, there were a few additional seconds between each of the six bouts in an Overground $10 \mathrm{~m}$ trial, and a few seconds spent before and after speed sweep and self-paced modes in the treadmill trials.

We calculated the time required for walking speed to converge in self-paced treadmill tests to determine the minimum duration of a test with reliable measurements. We observed that participants seemed to converge to steady speed in much less time than the approximately two minutes provided in self-paced walking speed tests. To determine the convergence time in Self-Paced $2 \mathrm{~min}$, we first calculated the mean and standard deviation of walking speeds during the last $20 \%$, or the last $24 \mathrm{sec}$ onds, of the trial. Then we found the moment when walking speed first entered the range of the mean plus or minus one standard deviation, and determined it to be the convergence time, $t_{c n v g}$. We determined the convergence distance in Self-Paced $150 \mathrm{~m}$ similarly by setting the threshold from the mean and standard deviation of the last $30 \mathrm{~m}$ of the trial. Note that the initial treadmill speed was $0.8 \mathrm{~m} \mathrm{~s}^{-1}$ in all the self-paced treadmill trials.

We assessed subject experience in each walking speed test with a survey in order to determine whether the selfpaced tests were comfortable and intuitive compared to the standard tests. Subjects rated two written statements for each test after completing all the walking trials. The statements were "it was comfortable walking" and "it was easy to choose my walking speed," and the subjects had 
five options: strongly disagree, disagree, neutral, agree, and strongly agree. We quantified the selections by assigning scores from 1 to 5 for strongly disagree to strongly agree, respectively.

The statistical significance of differences across walking speed tests, in terms of intra-subject variation, time to measure, and survey scores, was tested using two-way analysis of variance (ANOVA) accounting for different tests and subjects. If a significant effect of test type was found in ANOVA, we conducted paired-sample $t$-test for every pair of tests. We used significance level of $\alpha=0.05$.

\section{Results}

\section{Self-pacing Algorithm}

The proposed self-pacing controller successfully matched subject speed and kept subjects near the baseline position. In the exploration trial of the familiarization session, all subjects easily walked (or even ran) on the self-paced treadmill at a wide range of speeds (about 0 to $2 \mathrm{~ms}^{-1}$ ).

\section{Experiment 1: State Estimator}

The State Estimator and motion capture system were in close agreement as to the subject speed and position. The RMS differences between estimations of the Kalman filter and motion capture system during the six one-minute trials were $R M S_{\bar{v}}=0.023 \pm 0.003 \mathrm{~m} \mathrm{~s}^{-1}$ and $R M S_{\bar{p}}=$ $0.014 \pm 0.008 \mathrm{~m}$. Figure 3 shows the Kalman filter estimations of the subject speed and position, $v_{K F}$ and $p_{K F}$, and their mean values during each step, $\bar{v}_{K F}$ and $\bar{p}_{K F}$, as well as those values from the motion capture data. In addition, the speed and position calculated by merely integrating ground reaction forces are shown to diverge, demonstrating the necessity of the once-per-footstep measurement update of the Kalman filter. Time update using subject acceleration (Table 1: line 2) allows continuous and more accurate tracking of subject speed and position.

\section{Experiment 2: Self-selected Walking Speed Tests}

All ten subjects completed the self-selected walking speed test protocol. In the standard Overground $10 \mathrm{~m}$ test, the mean and standard deviation of the self-selected walking speeds were $1.32 \pm 0.18 \mathrm{~m} \mathrm{~s}^{-1}$, ranging from 0.98 to $1.79 \mathrm{~m} \mathrm{~s}^{-1}$. Leg length, defined as the distance between anterior iliac spine and the medial malleolus, explained $20 \%$ of the variance in self-selected walking speed $\left(R^{2}=0.20, p=0.01\right)$, which agrees with previous studies [1].

Walking speeds measured in Overground $150 \mathrm{~m}$ were close to those in Overground $10 \mathrm{~m}$. The fitted linear model was close to the identity line with a high correlation coefficient (Fig. 4-a). The mean and standard deviation of walking speeds were $1.35 \pm 0.19 \mathrm{~m} \mathrm{~s}^{-1}$. This result supports that the standard test, Overground $10 \mathrm{~m}$, reliably measures walking speed in longer distance walking.
Speeds in Manual Speed Selection were highly correlated with those in Overground $10 \mathrm{~m}$ but were slower overall. Walking speeds in Manual Speed Selection were $1.18 \pm 0.24 \mathrm{~m} \mathrm{~s}^{-1}$, which was significantly lower $(p=0.01)$ than those in Overground $10 \mathrm{~m}$ (Fig. 4-b). This result agrees with previous studies with similar treadmill speed selection tests $[10,12]$. The correlation value of $R=0.89$ between Manual Speed Selection and Overground $10 \mathrm{~m}$ is set as the benchmark for our self-paced treadmill tests.

Both Self-Paced 2 min and Self-Paced $150 \mathrm{~m}$ were highly correlated with Overground $10 \mathrm{~m}$. The correlation coefficients of the self-paced treadmill tests $(R=0.93$ and $R=0.94$ ) were slightly higher than for Manual Speed Selection (Fig. 4-c and d vs. b). The walking speeds in selfpaced treadmill tests were $1.23 \pm 0.28 \mathrm{~m} \mathrm{~s}^{-1}$ and $1.23 \pm 0.27$ $\mathrm{m} \mathrm{s}^{-1}$, respectively. The speeds were not significantly different from Overground $10 \mathrm{~m}$ speeds $(p=0.13$ in both tests) and were slightly closer than Manual Speed Selection speeds were. However, participants with slower overground walking speeds reduced their speed more on the treadmill. The three slowest subjects walked significantly slower in the self-paced treadmill tests compared to the standard test $\left(0.87 \pm 0.11\right.$ vs. $\left.1.11 \pm 0.07, p=6 \times 10^{-5}\right)$, while the remaining seven subjects did not $(1.38 \pm 0.15$ vs. $1.41 \pm 0.13, p=0.49$ ).

Walking speeds measured in Self-Paced $2 \mathrm{~min}$ and Self-Paced $150 \mathrm{~m}$ were very similar. The fitted model was close to the identity line $\left(v_{S P 150}=0.96 v_{S P 2}+0.06\right)$, and the correlation coefficient was very high $\left(R=0.98, p=7 \times 10^{-20}\right)$.

The intra-subject variabilities in all tests were low and were not significantly different $(p=0.49)$. The average across all tests and participants was $S D_{\text {intra }}=0.042 \pm$ $0.030 \mathrm{~m} \mathrm{~s}^{-1}$. The variability values of individual tests were all lower than $0.1 \mathrm{~m} \mathrm{~s}^{-1}$, which has been suggested as a threshold for clinical significance of differences in walking speed $[5,6,9]$.

The self-paced treadmill tests required about a third of the time required for Manual Speed Selection. The mean and standard deviation of the times required for a trial of each test were $T_{O G 10}=87 \pm 9 \mathrm{~s}$, $T_{O G 150}=124 \pm 16 \mathrm{~s}, T_{M S S}=371 \pm 141 \mathrm{~s}, T_{S P 2}=$ $125 \pm 1 \mathrm{~s}$, and $T_{S P 150}=138 \pm 35 \mathrm{~s}$. Walking speed test type had a significant effect on measurement time (ANOVA, $p=4 \times 10^{-37}$ ). All the tests were significantly different from each other (paired $t$-tests, $p<0.002$ ), except for Self-Paced 2 min and Self-Paced $150 \mathrm{~m}(p=$ $0.051)$ and for Overground $150 \mathrm{~m}$ and Self-Paced $2 \mathrm{~min}$ $(p=0.754)$. Manual Speed Selection took the longest on average and also was the most variable across subjects. The large time variation was due to some subjects having large gaps between the speeds identified to be faster or slower than comfortable speeds while others had smaller gaps. 
a

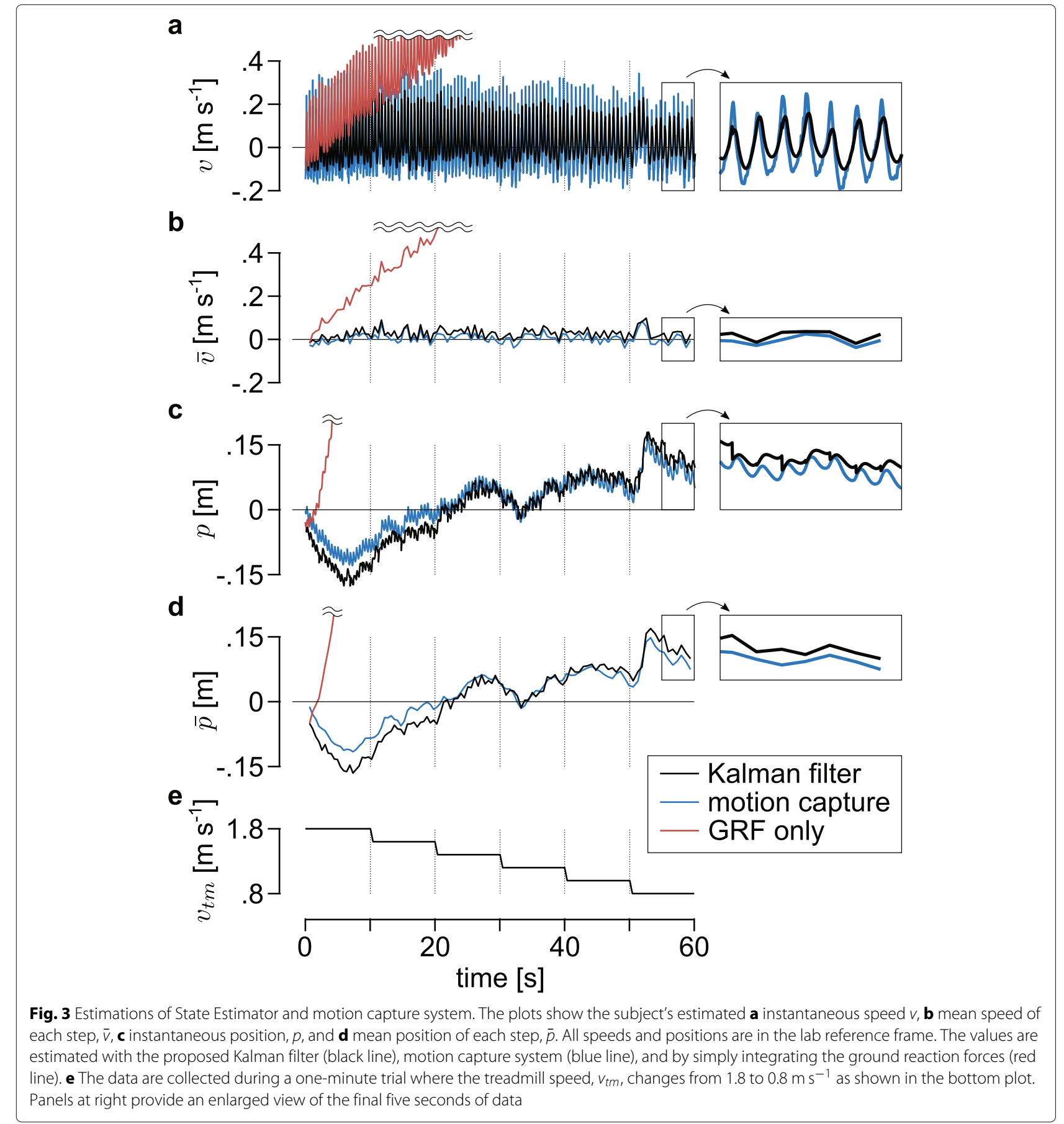

b

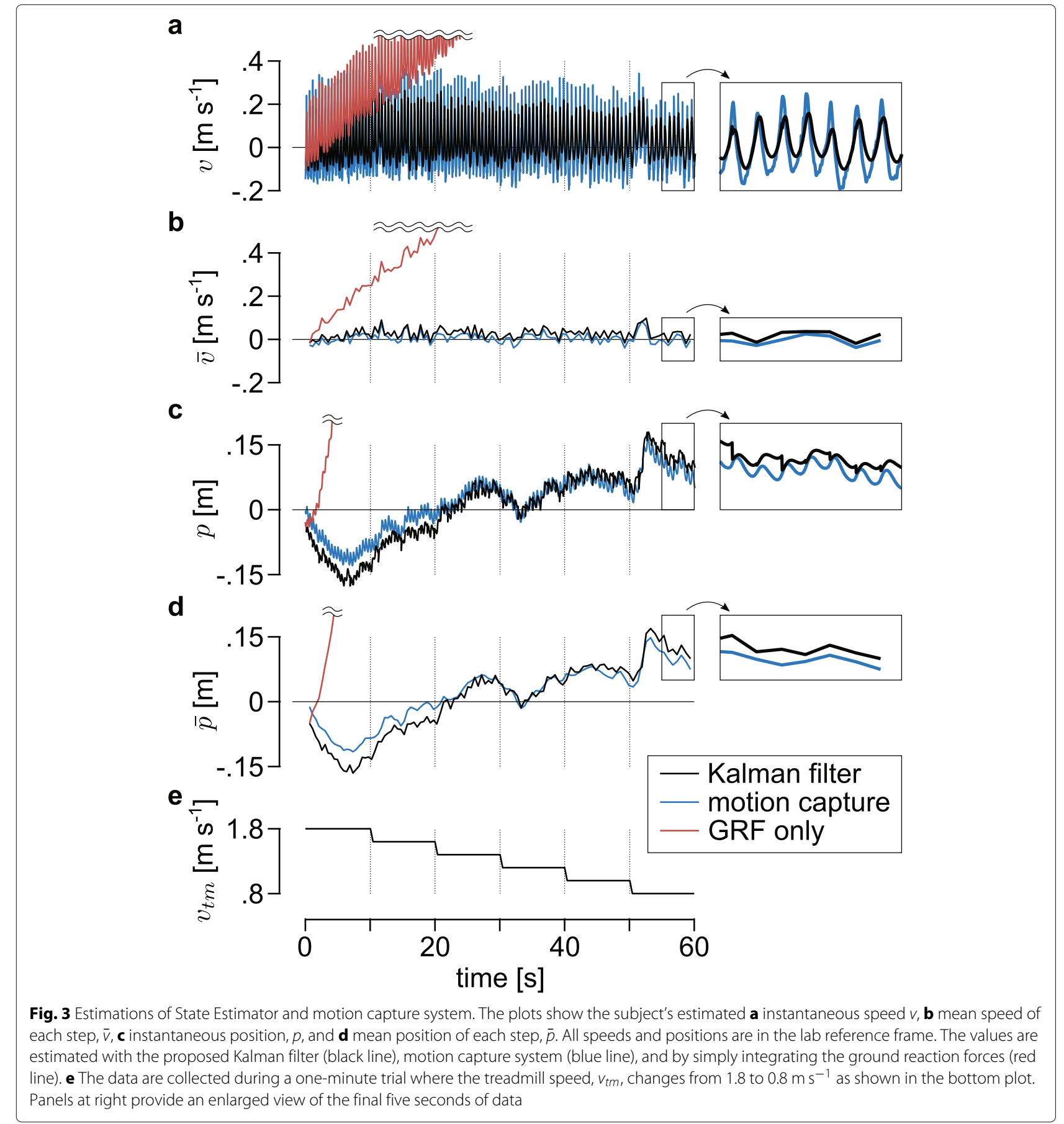

C

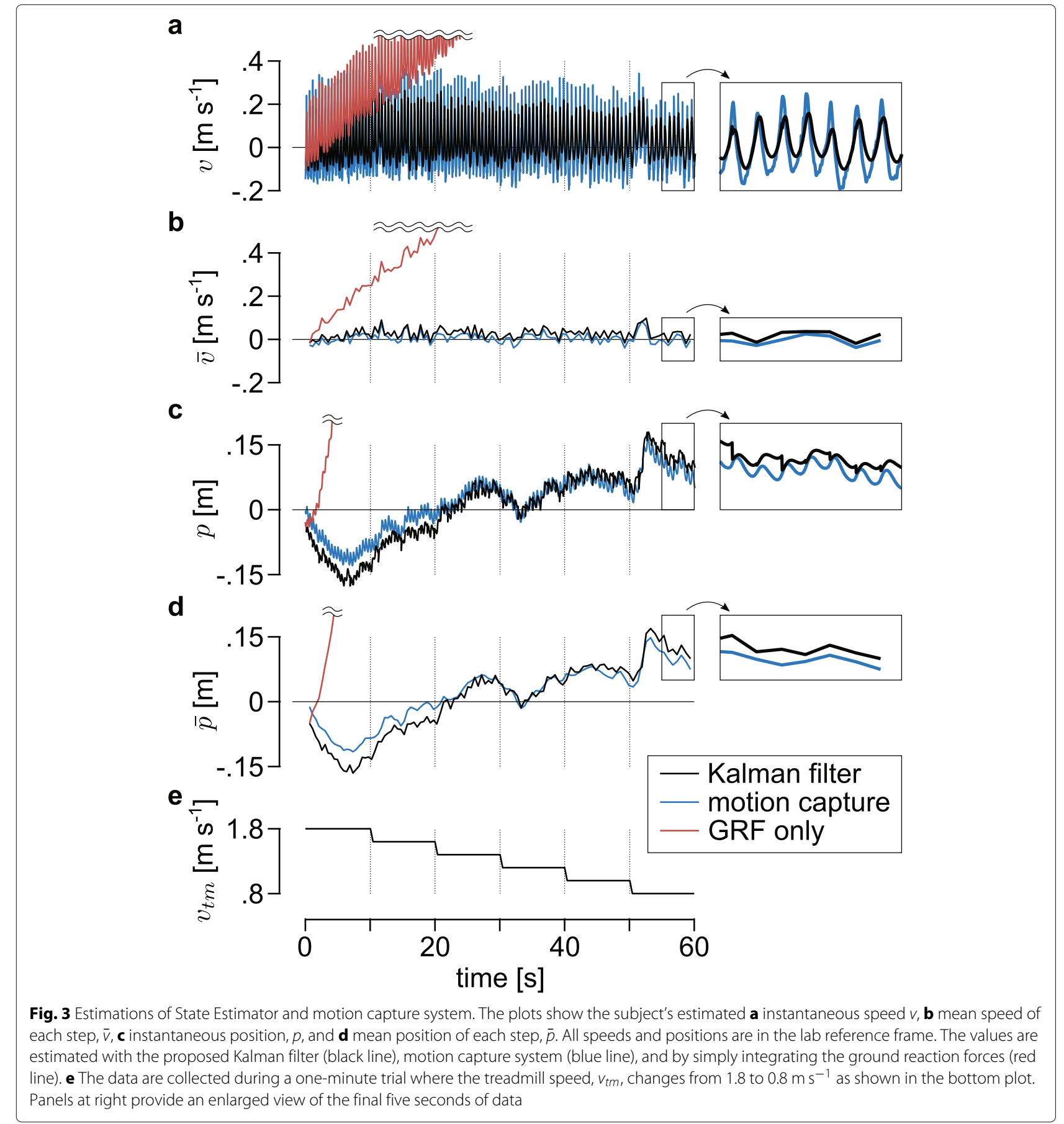

d
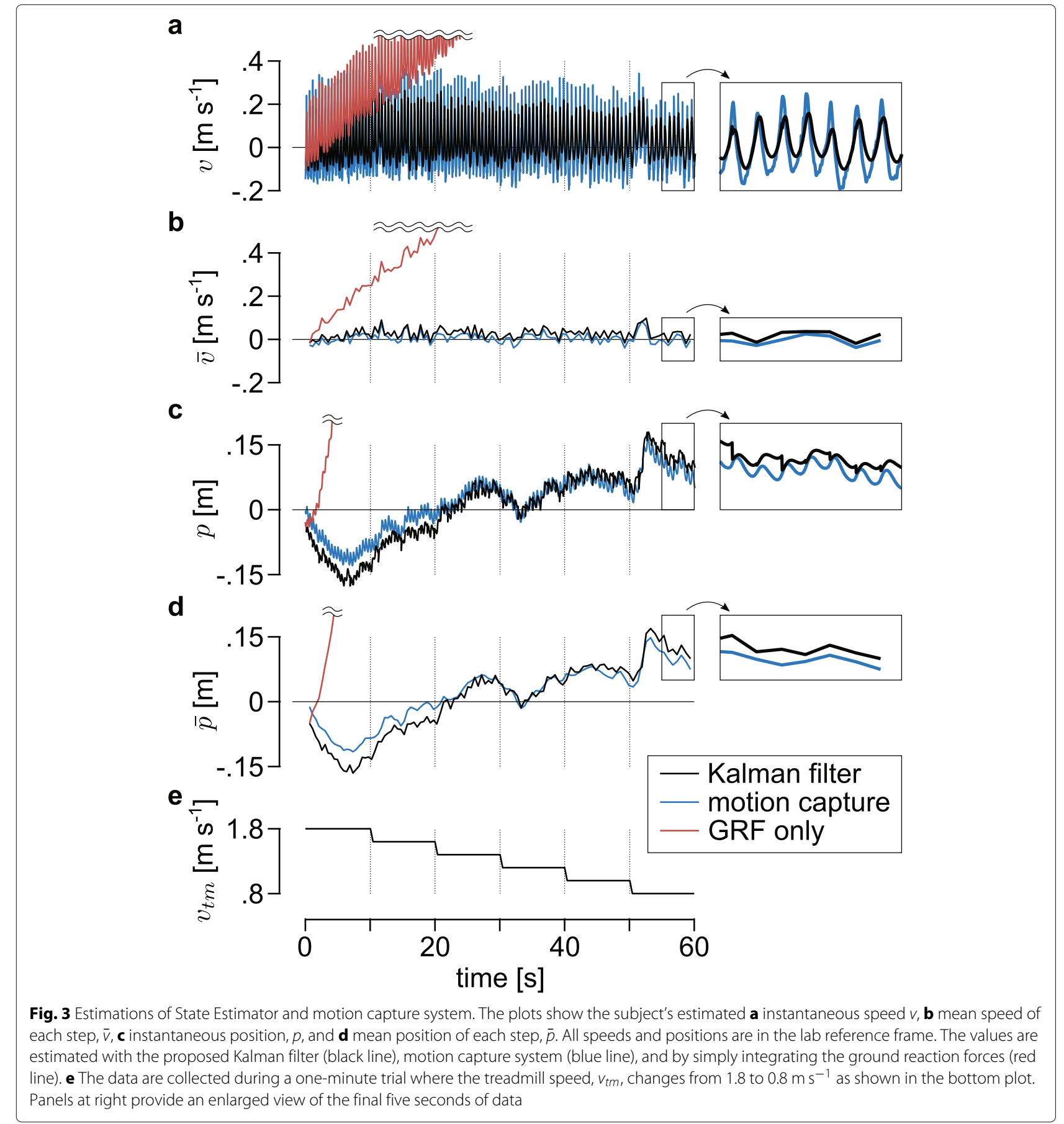

Analysis of speed convergence in the self-paced treadmill tests suggests that the preset time and distance can be much shorter than 2 min and $150 \mathrm{~m}$. The mean and standard deviation of the convergence time in Self-Paced 2 min were $t_{c n v g}=22 \pm 22 \mathrm{~s}$ while mean and standard deviation of convergence distance in Self-Paced $150 \mathrm{~m}$ were $d_{\text {cnvg }}=42 \pm 29 \mathrm{~m}$ (Fig. 5). This convergence distance corresponded to $t_{c n v g}=34 \pm 22 \mathrm{~s}$ in time, significantly longer than that in Self-Paced $2 \min (p=0.048)$. This result suggests that the times used in the current Self-Paced $2 \mathrm{~min}$ $\left(T_{S P 2}=125 \mathrm{~s}\right)$ and Self-Paced $150 \mathrm{~m}\left(T_{S P 150}=138 \mathrm{~s}\right)$ could be much shorter. For example, the average speed during the last five seconds of the first minute of the SelfPaced 2 min test is not statistically different from the current measure $(p=0.89)$. This would require about one sixth the time of the conventional treadmill speed test. 

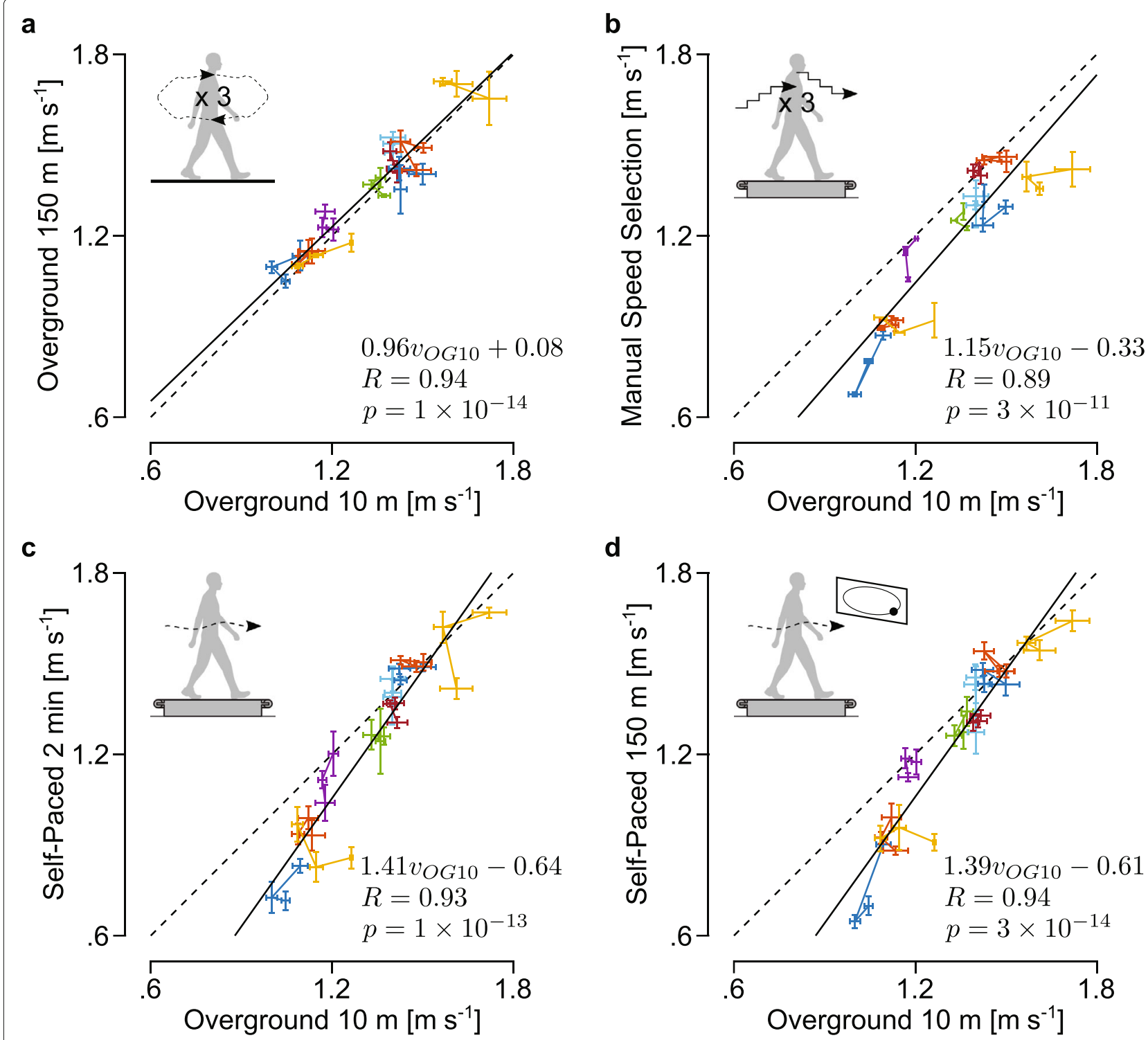

Fig. 4 Speeds measured in the self-selected walking speed tests. The self-selected walking speeds measured in a Overground $150 \mathrm{~m}$, b Manual Speed Selection, c Self-Paced $2 \mathrm{~min}$, and $\mathbf{d}$ Self-Paced $150 \mathrm{~m}$ are compared to those from Overground $10 \mathrm{~m}$. The data points relate a self-selected walking speed measured in a test to the one measured in the standard test in the same block. Each data point is a mean of four measurements (Fig. 2), with whiskers depicting \pm 1 standard deviation. The exception is for Manual Speed Selection, where the standard deviation is for two measurements because a pair of faster and slower than comfortable speeds are required to obtain one measurement of comfortable speed. Three data points from the same subject are connected with a line and marked in the same color. The linear model, correlation coefficient, and $p$-value for the fit are shown at the bottom right of each plot

The survey results suggested that subjects found walking at their comfortable speeds in the self-paced treadmill tests to be as comfortable as in the common treadmill speed selection test but not as comfortable as in overground tests. The mean and standard deviation of the scores for "it was comfortable walking" were $4.3 \pm 0.7$ for Overground $10 \mathrm{~m}, 4.4 \pm 0.5$ for Overground $150 \mathrm{~m}$, $3.5 \pm 1.0$ for Manual Speed Selection, $3.9 \pm 0.7$ for SelfPaced $10 \mathrm{~m}$, and $3.8 \pm 0.8$ for Self-Paced $150 \mathrm{~m}$, where 1 is strongly disagree and 5 is strongly agree. The scores for the "it was easy to choose my walking speed" statement were $4.4 \pm 0.7,4.5 \pm 0.7,3.0 \pm 1.2,3.3 \pm 0.7$ and $3.4 \pm 1.0$, respectively. Speed test type had a significant effect on survey results (ANOVA, $p=0.002$ and $1 \times 10^{-5}$, respectively). Comfort and ease of speed selection in self-paced tests were not significantly different from those in the conventional treadmill test (paired $t$-tests, $p>0.10$ ) but were worse than those in overground tests $(p<0.053)$. 


\section{a Self-Paced 2 min}

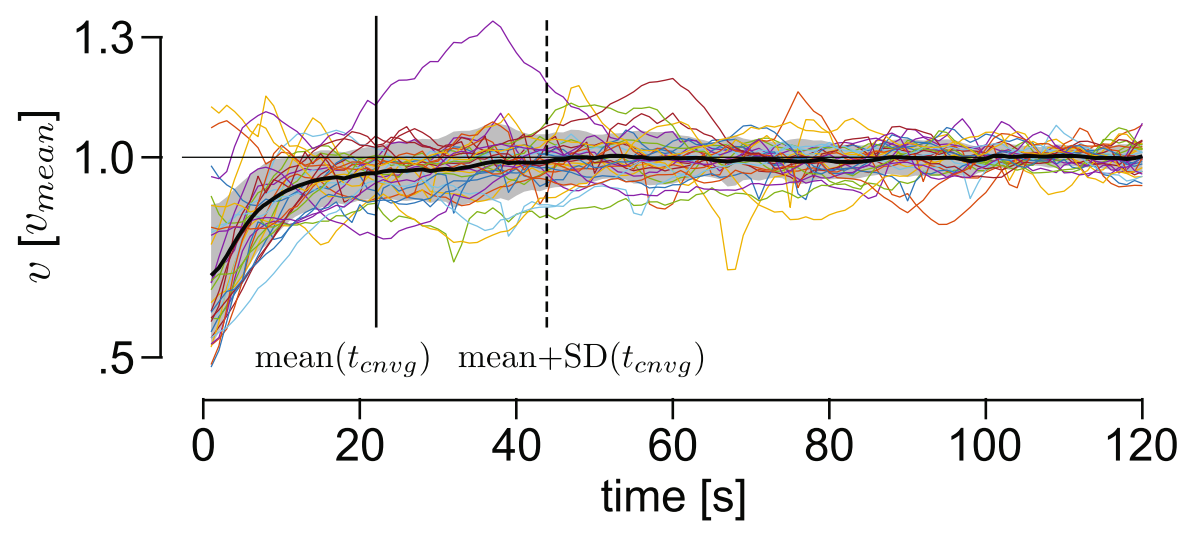

\section{b Self-Paced $150 \mathrm{~m}$}

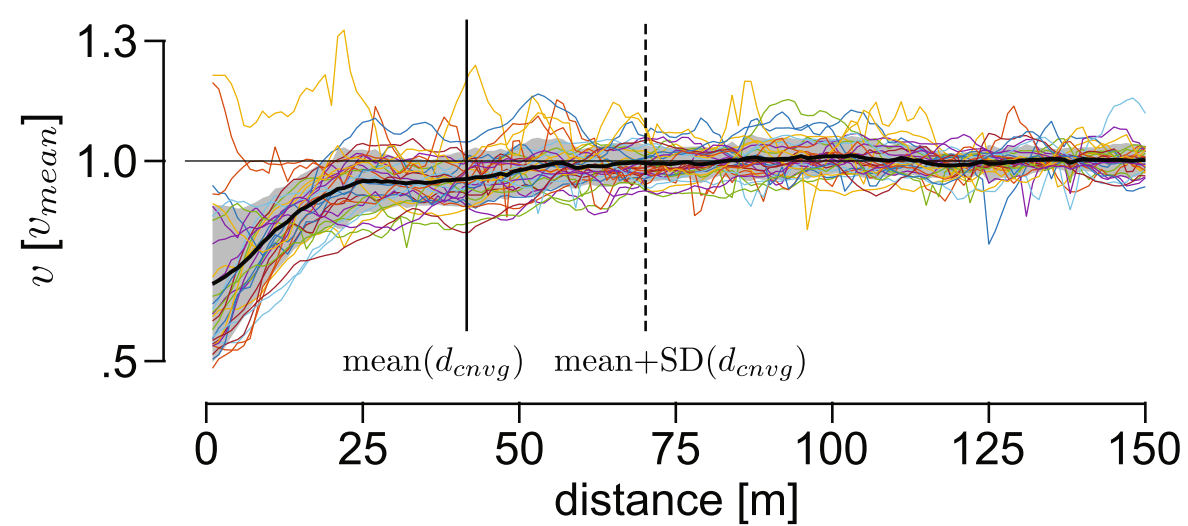

Fig. 5 Convergence of walking speeds in self-paced treadmill tests. Walking speeds normalized by final estimated speed in $\mathbf{a}$ Self-Paced 2 min and $\mathbf{b}$ Self-Paced $150 \mathrm{~m}$ tests. Walking speed from individual trials are shown in colored lines. The mean and \pm 1 standard deviation across all trials are shown as a black line and gray shaded area. The solid and dotted vertical lines indicate the mean and mean plus one standard deviation of convergence time and distance

\section{Discussion}

Our results indicate that the proposed self-paced treadmill can be used to measure self-selected walking speed. Subjects selected walking speeds in self-paced treadmill tests that were highly correlated with their speeds in the standard overground test. Intra-subject speed variations in the self-paced treadmill tests were low, demonstrating repeatability. The self-paced treadmill tests required only about a third of the time to complete of a common treadmill test, with no reduction in comfort or ease.

Although the walking speeds from self-paced treadmill tests highly correlated with the standard 10-meter walk test, the actual speeds were not the same. More specifically, subjects who walked at slow speeds in Overground $10 \mathrm{~m}$ walked even slower in Self-Paced 2 min and Self-Paced $150 \mathrm{~m}$ (Fig. 4-c,d). We can speculate different reasons for this observation. First, our self-pacing controller may be tuned better for normal and fast walking than walking at slow speeds.
However, that would not explain why the slow walking subjects also selected slower speeds in Manual Speed Selection (Fig. 4-b). Second, which is more compelling in our opinion, contextual changes [31-33] other than segment dynamics (i.e. force interactions between subjects and the treadmill or ground) may have a larger effect during slower walking. The influence of these contextual changes may depend on walking speed because control strategies may change for different speeds $[38,39]$ as modeling studies suggest slower walking should rely more on active balance control than on passive dynamics [40]. This hypothesis could be tested by studying how the amount of context-induced gait changes correlate with walking speed. Whatever the reason, the strong correlation between self-paced and overground speeds suggests that changes in self-selected walking speed on the self-paced treadmill will translate into changes during overground walking, though the absolute magnitudes may differ. 
Subjects selected to walk at very similar speeds on our self-paced treadmill whether they were walking for a preset time or a preset distance. This was unexpected because it would seem inconsistent with the minimum effort principle. So why did subjects walk at similar speeds in the preset time (Self-Paced $2 \mathrm{~min}$ ) and present distance (SelfPaced $150 \mathrm{~m}$ ) tests? First, subjects may have tried to fulfill the experimenter's expectation. We instructed the subjects to walk at their comfortable speed in all five tests, which the subjects may have interpreted as walking at a particular speed. However, such interpretation or intent of matching experimenter expectation was not apparent from subject feedback. Second, it could be that the objective of walking for a preset time was not clear to subjects because it is different enough from other walking tasks that they had experienced. Walking for a preset distance is close to walking to a target location, which is very common in daily life. Walking or running on a treadmill in a gym for a preset time as a workout might seem similar but is different from the preset time test in our study, in that the speed is usually set based on energy expenditure goals. For the unique task of walking for a preset time in an experiment, subjects may have aimed to walk in a way they were most familiar with, which is to walk for a preset distance. Regardless of the reason, all subjects in our study self-selected to walk at similar speeds in the preset time and preset distance tests. Therefore, we can use the preset time on a self-paced treadmill to measure self-selected walking speeds, which can be easier to administer than for preset distance.

The proposed self-pacing controller is different from most previous controllers in that it uses data from treadmill force plates to estimate subject speed and position. Therefore, it requires a force-instrumented treadmill, and subjects should not cross over the belts when stepping, which can interfere with their natural gait. However, stepping on the correct belt on an instrumented treadmill is a common requirement for gait studies [13], in which case, the self-pacing controller can be used with little overhead. We have previously tested other approaches that require additional parts on subjects, such as motion capture markers or string potentiometers, and those setups can easily increase the burden in complex gait experiments, such as studies on robotic exoskeletons or prostheses [14, 41]. Improving the performance of the self-pacing controller in the presence of cross-over steps would allow it to be used in additional protocols or when using singlebelt instrumented treadmills. To enable position updates during cross-over steps, the algorithm should be able to estimate the timing and position of new foot contacts without the assumption that each step is made on the corresponding belt. Using the COP estimated from GRFs combined from both belts and sensing abrupt changes in this COP could be an effective approach.
Another difference from most prior self-pacing controllers is that ours adjusts the treadmill speed only once per footstep. Most other self-paced treadmill controllers update treadmill speed at a higher frequency $(30 \sim 120 \mathrm{~Hz})$ [16-18]. If the treadmill speed instantaneously matches subject body speed, it will fluctuate within every stride due to natural speed oscillations in normal walking (Fig. 3a) and may introduce undesired treadmill dynamics. To minimize this effect, previous studies low-pass filtered the estimated body state with a low cutoff frequency (e.g. $2 \mathrm{~Hz}$ ), which can introduce time delays. Instead, our controller updates the treadmill speed once-per-footstep based on the mean values in that footstep. We find our approach to be conceptually more consistent with the control goal of matching walking speed, not instantaneous speed. A more thorough investigation of treadmill speed adjustment strategies could be instructive and might improve the self-pacing controller. For example, we use a simple heuristic control scheme (Eq. 4) with low control gains in matching subject speed and position, which is similar to previous approaches [16]. While higher gains can respond more quickly to speed and position changes, we empirically found lower gains to be stable and reliable for walking at steady speeds and moderate speed changes. Gain scheduling that matches large speed changes as well as steady walking would extend the potential use of self-paced treadmills in gait studies.

In the future, this self-pacing controller could be extended to address additional locomotion behaviors and its usability could be improved. We expect that the controller could be extended to running and to inclined and declined surfaces with only minimal changes. The human response to the controller under these conditions would need to be tested in an experiment similar to the one described in this study. It should be possible to create a version of the self-pacing software that runs on a personal computer without a real-time target machine, which would allow additional researchers to use the technique. We plan to update our repository with such extensions as they occur [42].

The proposed self-paced treadmill can be used in rehabilitation treatment and in gait assistance research but should be re-validated for substantially different populations or tasks. All of the subjects that participated in our experiment found walking on the self-paced treadmill intuitive and easy. However, the subtle dynamics and apparent contextual differences induced by self-paced treadmills may have a larger effect for subjects with different health status or for different locomotion tasks. For example, it has been reported that children with cerebral palsy experienced larger changes in gait on a self-paced treadmill than typically developing children [35]. Nevertheless, for healthy adults walking at typical speeds, self-selected walking speed on this self-paced 
treadmill can be used as an indication of overground walking behavior.

\section{Conclusions}

We presented a self-paced treadmill controller for forceinstrumented treadmills that can be used to measure self-selected walking speeds. The controller is adapted from a previous study [15] and solely uses force-plate data to estimate and adapt to the subject's walking speed and position. To validate its use for measuring self-selected walking speeds, we compared walking speeds measured in a range of walking speed tests, where the subjects were instructed to walk at or select their comfortable speed. The tests using our self-paced treadmill measured walking speeds that were highly correlated with those from the standard overground test. The differences in the measured speeds from the self-paced treadmill and overground tests were small and consistent. The low intrasubject variability of measured speeds supports the reliability of the self-paced treadmill tests. The times required for the self-paced treadmill tests were a few times less than that for a common treadmill test, where subjects manually select their comfortable speeds, with the potential for further substantial reductions in duration. Subjects found the self-paced treadmill tests to be as comfortable and easy as the common treadmill test. These results demonstrate that measurements of self-selected walking speed made using the self-paced treadmill are relevant to overground conditions, and that the self-paced treadmill provides a strong alternative to manual speed selection on an instrumented treadmill. We provide a complete description and code for the self-pacing controller and graphical user interface to facilitate use by other gait researchers and clinicians [36].

\section{Abbreviations \\ ANOVA: analysis of variance; GRF: ground reaction force; COP: center of pressure; RMS: root mean square}

\section{Acknowledgements}

The authors thank all participants of this study as well as Maxwell Donelan and Arthur Kuo for discussions about preset time and preset distance walking.

\section{Authors' contributions \\ SS and SC conceived the study and designed the experiment, SS and HC developed the algorithm, SS conducted experiments and analyzed data, SS drafted the manuscript, SS and SC edited the manuscript, and all authors approved the submitted manuscript.}

\section{Funding}

This material is based upon work supported by the National Science Foundation under Grant No. CMMI-1734449.

\section{Availability of data and materials}

Main data of the study are included in the supplementary information files. All data collected in the study are available from the corresponding author on reasonable request. The code for self-paced treadmill is available in the self-paced-treadmill repository on GitHub [36].
Ethics approval and consent to participate

Ethical approval for the study was granted by the Stanford University

Institutional Review Board. All participants provided written informed consent.

\section{Consent for publication}

Not applicable.

\section{Competing interests}

The authors declare that they have no competing interests.

Received: 19 November 2019 Accepted: 3 April 2020

Published online: 03 June 2020

\section{References}

1. Bohannon RW. Comfortable and maximum walking speed of adults aged 20 —79 years: reference values and determinants. Age Ageing. 1997;26(1): 15-9.

2. Ralston HJ. Energy-speed relation and optimal speed during level walking. Internationale Zeitschrift für Angewandte Physiologie Einschliesslich Arbeitsphysiologie. 1958;17(4):277-83.

3. Srinivasan M. Optimal speeds for walking and running, and walking on a moving walkway. Chaos: An Interdiscip J Nonlinear Sci. 2009;19(2):026112.

4. Song S, Geyer H. Predictive neuromechanical simulations indicate why walking performance declines with ageing. The J Physiol. 2018;596(7): 1199-210.

5. Purser JL, Weinberger M, Cohen HJ, Pieper CF, Morey MC, Li T, Williams GR, Lapuerta P. Walking speed predicts health status and hospital costs for frail elderly male veterans. J Rehabil Res Dev. 2005;42(4):

6. Hardy SE, Perera S, Roumani YF, Chandler JM, Studenski SA Improvement in usual gait speed predicts better survival in older adults. J Am Geriatr Soc. 2007;55(11):1727-34.

7. Goldie PA, Matyas TA, Evans OM. Deficit and change in gait velocity during rehabilitation after stroke. Arch Phys Med Rehabil. 1996;77(10): 1074-82.

8. Wolf SL, Catlin PA, Gage K, Gurucharri K, Robertson R, Stephen K. Establishing the reliability and validity of measurements of walking time using the emory functional ambulation profile. Phys Ther. 1999;79(12): 1122-33.

9. Fritz S, Lusardi M. White paper:"walking speed: the sixth vital sign". J Geriatr Phys Ther. 2009:32(2):2-5.

10. Dal U, Erdogan T, Resitoglu B, Beydagi H. Determination of preferred walking speed on treadmill may lead to high oxygen cost on treadmill walking. Gait \& Posture. 2010;31(3):366-9.

11. Nagano H, Begg RK, Sparrow WA, Taylor S. A comparison of treadmill and overground walking effects on step cycle asymmetry in young and older individuals. J Appl Biomech. 2013;29(2):188-93.

12. Malatesta D, Canepa M, Fernandez AM. The effect of treadmill and overground walking on preferred walking speed and gait kinematics in healthy, physically active older adults. Eur J Appl Physiol. 2017;117(9): 1833-43.

13. Lee SJ, Hidler J. Biomechanics of overground vs. treadmill walking in healthy individuals. J Appl Physiol. 2008;104(3):747-55.

14. Zhang J, Fiers P, Witte KA, Jackson RW, Poggensee KL, Atkeson CG, Collins SH. Human-in-the-loop optimization of exoskeleton assistance during walking. Science. 2017;356(6344):1280-4.

15. Feasel J, Whitton MC, Kassler L, Brooks FP, Lewek MD. The integrated virtual environment rehabilitation treadmill system. IEEE Trans Neural Syst Rehabil Eng. 2011;19(3):290-7

16. Sloot $L$, Van der Krogt MM, Harlaar J. Self-paced versus fixed speed treadmill walking. Gait \& Posture. 2014:39(1):478-84.

17. Yoon J, Park H-S, Damiano DL. A novel walking speed estimation scheme and its application to treadmill control for gait rehabilitation. J Neuroeng Rehabil. 2012;9(1):62.

18. Plotnik M, Azrad T, Bondi M, Bahat $Y$, Gimmon $Y$, Zeilig G, Inzelberg R, Siev-Ner I. Self-selected gait speed-over ground versus self-paced treadmill walking, a solution for a paradox. J Neuroeng Rehabil. 2015;12(1):20

19. GRAIL - Motekforce Link. https://www.motekmedical.com/product/grail/, Accessed: 2-20-2020 
20. Sloot LH, Harlaar J, Van der Krogt MM. Self-paced versus fixed speed walking and the effect of virtual reality in children with cerebral palsy. Gait \& Posture. 2015;42(4):498-504.

21. Van der Krogt MM, Sloot LH, Buizer Al, Harlaar J. Kinetic comparison of walking on a treadmill versus over ground in children with cerebral palsy. J Biomech. 2015;48(13):3577-83.

22. Fung J, Richards CL, Malouin F, McFadyen BJ, Lamontagne A. A treadmill and motion coupled virtual reality system for gait training post-stroke. CyberPsychol Behav. 2006;9(2):157-62.

23. Gates DH, Darter BJ, Dingwell JB, Wilken JM. Comparison of walking overground and in a computer assisted rehabilitation environment (CAREN) in individuals with and without transtibial amputation. J Neuroeng Rehabil. 2012;9(1):81.

24. Kim J, Gravunder A, Park H-S. Commercial motion sensor based low-cost and convenient interactive treadmill. Sensors. 2015;15(9):23667-83.

25. Minetti AE, Boldrini L, Brusamolin L, Zamparo P, McKee T. A feedbackcontrolled treadmill (treadmill-on-demand) and the spontaneous speed of walking and running in humans. J Appl Physiol. 2003;95(2):838-43.

26. Von Zitzewitz J, Bernhardt M, Riener R. A novel method for automatic treadmill speed adaptation. IEEE Trans Neural Syst Rehabil Eng. 2007;15(3):401-9.

27. Sloot L, Van der Krogt MM, Harlaar J. Energy exchange between subject and belt during treadmill walking. J Biomech. 2014;47(6):1510-3.

28. Snaterse M, Ton R, Kuo AD, Donelan JM. Distinct fast and slow processes contribute to the selection of preferred step frequency during human walking. J Appl Physiol. 2011;110(6):1682-90.

29. Graham JE, Ostir GV, Kuo Y-F, Fisher SR, Ottenbacher KJ. Relationship between test methodology and mean velocity in timed walk tests: a review. Arch Phys Med Rehabil. 2008;89(5):865-72.

30. Seethapathi $N$, Srinivasan M. The metabolic cost of changing walking speeds is significant, implies lower optimal speeds for shorter distances, and increases daily energy estimates. Biology letters. 2015;11(9):20150486.

31. Mohler BJ, Thompson WB, Creem-Regehr SH, Pick HL, Warren WH. Visual flow influences gait transition speed and preferred walking speed. Exp Brain Res. 2007;181(2):221-8.

32. O'Connor SM, Donelan JM. Fast visual prediction and slow optimization of preferred walking speed. J Neurophysiol. 2012;107(9):2549-59.

33. McIntosh GC, Brown SH, Rice RR, Thaut MH. Rhythmic auditory-motor facilitation of gait patterns in patients with Parkinson's disease. J Neurol Neurosurg Psychiatry. 1997;62(1):22-6.

34. Brinkerhoff SA, Murrah WM, Hutchison Z, Miller M, Roper JA. Words matter: Instructions dictate "self-selected" walking speed in young adults. Gait \& Posture. 2019. https://www.sciencedirect.com/science/article/abs/ pii/S0966636219303522.

35. Van der Krogt MM, Sloot LH, Harlaar J. Overground versus self-paced treadmill walking in a virtual environment in children with cerebral palsy. Gait \& Posture. 2014;40(4):587-93.

36. Self-paced-treadmill repository. https://github.com/smsong/self-pacedtreadmill/tree/JNER2020, Accessed: 2-20-2020.

37. Chan WL, Pin TW. Reliability, validity and minimal detectable change of 2-minute walk test, 6-minute walk test and 10-meter walk test in frail older adults with dementia. Exp Gerontol. 2019;115:9-18.

38. Helbostad $J$, Moe-Nilssen R. The effect of gait speed on lateral balance control during walking in healthy elderly. Gait \& Posture. 2003;18(2):27-36.

39. Fettrow T, Reimann H, Grenet D, Crenshaw J, Higginson J, Jeka JJ. Walking cadence affects the recruitment of the medial-lateral balance mechanisms. Frontiers in Sports and Active Living. 2019;1:40.

40. Hobbelen DG, Wisse M. Controlling the walking speed in limit cycle walking. Int J Robot Res. 2008;27(9):989-1005.

41. Chiu VL, Voloshina A, Collins S. An ankle-foot prosthesis emulator capable of modulating center of pressure. IEEE Trans Biomed Eng. 2019;67(1):166-176.

42. Self-paced-treadmill repository. https://github.com/smsong/self-pacedtreadmill, Accessed: 2-20-2020.

\section{Publisher's Note}

Springer Nature remains neutral with regard to jurisdictional claims in published maps and institutional affiliations.

Ready to submit your research? Choose BMC and benefit from:

- fast, convenient online submission

- thorough peer review by experienced researchers in your field

- rapid publication on acceptance

- support for research data, including large and complex data types

- gold Open Access which fosters wider collaboration and increased citations

- maximum visibility for your research: over $100 \mathrm{M}$ website views per year

At $\mathrm{BMC}$, research is always in progress.

Learn more biomedcentral.com/submissions 